\title{
Translating Research into Practice: The Participatory Expert Panel Approach
}

\author{
Robin E. Estabrook ${ }^{1}$, Russell K. Schutt ${ }^{*}, 2$ and Mary Lou Woodford ${ }^{3}$ \\ ${ }^{I}$ Department of Sociology, University of Illinois, Champaign/Urbana, IL, USA \\ ${ }^{2}$ Department of Sociology, University of Massachusetts Boston and Department of Psychiatry, Harvard Medical School, \\ Boston, MA, USA \\ ${ }^{3}$ Women's Health Network, Massachusetts Department of Public Health, Boston, MA, USA
}

\begin{abstract}
Effective translation of research results into programmatic change continues to be the exception to the norm, in spite of increasing recognition to the importance of translational efforts and innovative approaches to the translation process. We focus attention in this article on a participatory expert panel approach that can improve translation of research into practice by engaging a wide range of stakeholders in reviewing research results and program operations. We demonstrate how we used this process to improve the translation of research concerning the Massachusetts Women's Health Network - a state- and federally-funded program that offers screening services to low income women at risk of breast and cervical cancer who lack health insurance. Interviews with selected participants provide insight into the expert panel process and help to indicate its effectiveness. We conclude with suggestions for improving this approach to translation and offer some cautions based on the Massachusetts experience.
\end{abstract}

\section{INTRODUCTION}

Although the United States spends approximately $\$ 100$ billion annually on biomedical and health care research, much of this investment does not lead to improvements in health and well-being, or even changes in health care programs, due to inadequate dissemination and implementation of the findings [1-4]. The results of this failure to translate research findings into health care policies and programs include suboptimal quality of care [2] and excessive health care disparities [5]. Public health screening and prevention programs often fail to reach large fractions of the target population, to use the most effective and efficient methods, or to achieve the desired behavioral outcomes.

We describe and analyze a participatory expert panel process designed to improve the operation and outcomes of the Women's Health Network, a Massachusetts program for low-income uninsured and underinsured women that delivers screening services to those at risk of breast and cervical cancer, as well as cardiovascular disease. The program is funded in part by the CDC's National Breast and Cervical Cancer Early Detection Program (NBCCEDP) and its WellIntegrated Screening and Evaluation for Women Across the Nation program (WISEWOMAN). The project PI (RKS) and WHN program director (MLW) developed the Reviewing the Past, Planning the Future project (RPPF) in order to translate into new policies and practices the results of evaluation research about the program and the successful practices identified in similar programs in other states.

*Address correspondence to this author at the Department of Sociology, University of Massachusetts Boston and Department of Psychiatry, Harvard Medical School, Boston, MA, USA; E-mail: rschutt@bidmc.harvard.edu

\section{THE TRANSLATION PROCESS}

The translation process can have different meanings to different researchers and can involve different stages at different times. Lomas [6] identified three steps in the translation process: diffusion-publicizing research findings and other relevant information; dissemination - tailoring the information for the intended audience(s); and implementation - highlighting the implications of the information for a specific audience. Using a broader conceptualization, Glasgow [7] defined dissemination as the key translation process: "The active promotion or support of a program to encourage its widespread adoption, dissemination involves the adaptation, evaluation, implementation, and maintenance of an intervention." In this article, we focus on dissemination and implementation, rather than on broader publicity efforts.

We use two questions to distinguish four alternative approaches to the translation process: (1) Are the roles of researcher and practitioner separated or integrated? (2) Do translation activities occur simultaneously with or sequentially after the research activities? The different translation approaches distinguished by the four possible combinations of answers to these questions are represented in Table 1. The traditional evaluation research approach both separates the researcher's role from that of the practitioner and anticipates a translation process after the research has been concluded. The process of adopting Evidence-Based Practices falls within this category. The researcher's role also remains separate from the practitioner role when researchers provide consultation or training services as a component of or in interaction with program operations.

Participatory action research (PAR) engages practitioners in the research process from its inception through data collection and analysis as well as while formulating and imple- 
Table 1. Alternative Research and Practice Roles in the Translation Process

\begin{tabular}{|c|c|c|c|}
\hline & & \multicolumn{2}{|c|}{ Role Integration } \\
\hline & & Separate & Integrated \\
\hline \multirow{2}{*}{ 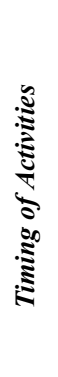 } & 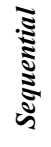 & $\begin{array}{l}\text { Traditional evaluation } \\
\text { research, EBP }\end{array}$ & $\begin{array}{l}\text { Participatory } \\
\text { Expert Panel }\end{array}$ \\
\hline & 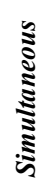 & $\begin{array}{l}\text { Consultation or } \\
\text { Training }\end{array}$ & $\begin{array}{c}\text { Participatory } \\
\text { Action Research }\end{array}$ \\
\hline
\end{tabular}

menting recommendations [8-10]. By contrast, the Participatory Expert Panel process we describe integrates the roles of practitioner and researcher after research has been completed. Although recent scholarship on the translation process has given most attention to PAR, we believe that a participatory expert panel can often play a unique and vital role in improving the translation process.

A Participatory Expert Panel brings together academic researchers, practitioners, policy-makers and other stakeholders to review and debate the implications of research on a program and to formulate recommendations for improvement. This process requires constant communication between panel members and recognizes that effective translation must integrate multiple sources of information in order to develop conclusions about their implications $[11,12]$. The participatory expert panel process engages the different interconnected elements of the complex adaptive systems through which services are delivered in a coordinated review process, thus facilitating identification of possibly unintended effects of change [13]. By bringing practitioners into a dialog with researchers, the participatory expert panel process seeks to increase the likelihood that interventions identified as optimal can actually be implemented into health systems [14-18].

Of course expert panels are often used to review scientific findings and develop summaries of research and recommendations for practice [19]. What we emphasize is the value of using Participatory Expert Panels as a vital element in the ongoing translation process and the importance of including practitioners and other stakeholders in the expert panel. The participatory expert panel process that we describe and analyze was not oriented primarily to producing a consensus report, but instead to developing and debating specific recommendations for translating research results into practice.

\section{THE PROJECT}

The Women's Health Network provides testing and referral services to low-income uninsured and underinsured women in Massachusetts who are at risk for breast or cervical cancer as well as prevention services to reduce the risk of cardiovascular disease among low income women. WHN is administered by the Massachusetts Department of Public Health and funded by the Commonwealth of Massachusetts and by the United States Centers for Disease Control and Prevention's (CDC) National Breast and Cervical Cancer Early Detection Program (NBCCEDP) and its WellIntegrated Screening and Evaluation for Women Across the Nation program (WISEWOMAN). At the time of the expert panel project, the Massachusetts Department of Public Health contracted with 26 different health care organizations that provided eligibility determination, enrollment, provision of services for breast and cervical cancer screening, as well as case management and patient navigation [20].

The Massachusetts Women's Health Network has been funded by the CDC's NBCCEDP since 1993 and has demonstrated successful integration of WISEWOMAN at six of the 23 contractor locations. Massachusetts was one of three original states to be funded to provide WISEWOMAN services. Although a higher fraction (45\%) of the eligible population is enrolled in the Massachusetts WHN for breast and cervical cancer screening and diagnostic services, close to $15 \%$ were also able to receive cardiovascular screening, risk reduction education and lifestyle interventions through the federal WISEWOMAN funding. Given the different focus of the WISEWOMAN program, risk reduction education and lifestyle interventions to reduce cardiovascular risk, the denominator for calculating the rate of coverage is inherently ambiguous, but the fact that only 6 of the 26 WHN contractors were able to deliver heart disease and stroke prevention services indicates insufficient delivery of WISEWOMAN services. The desire to achieve broader coverage for both NBCCEDP and WISEWOMAN services was a primary motivation for a translation effort.

In January 2005, the Massachusetts Department of Public Health funded a 6-month effort termed the Women's Health Network Project: Reviewing the Past, Planning the Future (RPPF). RPPF objectives were to review research relevant to the WHN, to examine similar programs in other states, and to translate the implications of data from these sources into new program practices. The project was designed and directed by coauthor Schutt in consultation with coauthor and WHN director Woodford. DPH did not require that the RPPF focus on any particular program areas nor consider the budgetary implications of desired changes; instead, RPPF participants were encouraged to be innovative and ambitious, as well as realistic.

The RPPF project began with formation of a 13-person Executive Steering Committee (ESC) composed of the WHN program director, the RPPF director, five academic experts on related community health programs, three leaders of hospital-based health research and policy programs, two program managers and one nursing PhD student. The ESC met six times during the project to formulate plans and review project operations [21]. Each Executive Steering Committee member chaired one of seven task forces that represented the range of issues under consideration: Medical Knowledge \& Health Care Technology: Breast \& Cervical Cancer Screening \& Intervention; Medical Knowledge \& Health Care Technology: CVD Screening \& Intervention; Health Care Disparities \& Barriers to Health Care Access; Fiscal Management \& Business Operations; Case Management; Health Care Delivery Systems; and Education, Outreach \& Enroll- 
ment. Six graduate research assistants, supervised by the project director and aided by project administrative assistant Elizabeth Cruz, supported the work of the task forces by arranging meetings, recording minutes, searching literature, investigating other programs and writing research reviews. A composite annotated bibliography was constructed by task force RAs and shared throughout the project. The WHN director assigned one staff member to each task force in order to provide detailed information about program operations and to fulfill requests for additional information.

The participatory expert panel itself consisted of 93 academic health care policy experts, medical doctors and researchers, cancer survivors, advocacy group members, program directors and staff, and Executive Steering Committee members. Expert panel members joined one task force, which included between 10 and 15 members who met in person or through conference calls between 4 and 8 times. The entire expert panel met for one full day at the project's start and again at its conclusion. These expert panel conferences consisted of presentations by the project's director and the WHN director, reports from each task force, and short task force meetings. Throughout this process, task force members reviewed research results, program operations, and the operation of similar programs in other states. The task force meetings at the final expert conference focused on integrating recommendations from the different task forces

Midway through the project, a special research meeting was held at which representatives of each task force discussed reports on all relevant research on the WHN program. Research presented at this meeting and available to the members of each task force were an evaluation of case management in WHN [20], a qualitative study of WHN operations, a study conducted by a WHN researcher of satisfaction with WHN services, and an analysis of service delivery data. The RA for each task force also prepared a report summarizing the body of prior research about the specific issues the task force was considering and describing similar programs in other states. In total, the task forces reviewed five reports of evaluation research about the WHN, over 500 scholarly articles, and 25 comparison programs [22]. The task forces drew on this material as they formulated recommendations that were presented at the final Expert Panel meeting and incorporated in the final project report [21].

\section{RESEARCH METHODS}

Our evaluation of the RPPF project is based on project documents, including notes of every task force meeting and open-ended interviews with a purposive sample of 13 participants [23]. The 65 different task force meetings throughout the project represented 700 person hours of work, with minutes recorded by RAs at each meeting using a standardized template. An open-ended semi-structured interview schedule was designed by all three co-authors for the sample of thirteen. Interviews were conducted by the first author, who had been a research assistant for a project task force but could credibly promise confidentiality to all interviewees. The other two co-authors, respectively, the project director and the WHN director, received summaries of and excerpts from the interviews but were at no time given complete transcripts or other information to identify the sources of specific comments. All procedures were approved by the Institutional Review Board of the University of Massachusetts Boston.

The thirteen interviewees were selected to represent the various work roles of expert panel participants (physicians, academic researchers, nurses, program directors) and different levels of project involvement (project leadership, executive steering committee, and task force membership). The resulting sample consisted of five task force chairs, the project's director (RKS), one DPH staff member, and four participants who were members of different task forces. Most interviewees had had previous contact with the WHN prior to the expert panel project and most had also been involved previously in academic projects. Four additional expert panel participants declined a request for an interview--two due to having changed employers and two due to scheduling difficulties.

Interviewees were asked to describe their work history, their prior experience with the WHN, and the extent of their involvement in the RPPF project overall and in a specific task force. Interview questions focused on a detailed description of task force activities and engagement in the expert panel meetings and on an evaluation of the quality of meetings, the sufficiency of evidence reviewed, and satisfaction with project leadership, the project report and the task force recommendations. Respondents were also asked to assess the apparent impact of the project, including the specific recommendations adopted by the health care policy consultant group.

We present data that provide more details about the expert panel process and that identifies reactions to various elements of that process. We first present comments about the research reviewed and then about the elements of the expert panel: the task forces, the Executive Steering Committee, and the Expert Panel itself. A separate section reviews comments about the work of the consultant group hired to develop implementation plans. The final section reports comments on the project overall.

\section{FINDINGS}

\section{Research}

Respondents reported an extensive amount of research used in the project. Although most participants didn't themselves "conduct research" per se, they reviewed prior research and other programs procedures. Two-thirds of the respondents said that looking into what was being done in other states was most helpful. Program comparisons allowed task forces to form recommendations based on what was said to already work for similar programs. Specifically, one-third of the interviewees identified a conference call held with other states to be the most helpful in forming their recommendations: "The most helpful research was the information about what other states were doing. We were able to correlate that with the goals of the Massachusetts program."

Ten of the 13 respondents were confident that research had informed their recommendations, although several believed that more research could have been done had the timeframe been extended. However, within the given timeframe most believed the research was adequate. Further, as one respondent remarked, 
It is fair to say we reviewed the best research from around the country pertinent to our work. Looking at the final report and the research summaries, it was really a great deal of research and a variety of sources.

\section{Task Force Process}

As indicated through transcribed meeting minutes, once the task forces were formed, teamwork principles were continuously applied and stressed. Throughout the project the task force leaders sought contributions from the entire group and all recommendations were made through consensus or, when consensus could not be reached, by a vote to determine the majority opinion. Extensive communication and collaboration were identified as common across all task forces. Members brainstormed to identify problems with the current system, decide what their main questions should be, develop a strategy to answer their questions, and develop their recommendations. At points in the project where information overlapped, the task forces worked closely together to assure that any overlaps were complementary.

When asked about their task force experience, interviewees mostly had positive things to say. Three-quarters of the respondents reported that members of their task forces worked well together. Six in ten reported that there was much open discussion which helped them to reach consensus and avoid potential problems. For example, "Not that many problems came up, we were all on the same page. There was lots of open discussion which helped prevent problems in the first place." Others concurred that task force members rarely had any differences, but when they did, they were easily addressed through discussion and consensus, one observing,

\begin{abstract}
We largely worked to a consensus; there were not many differences. We had good communication, people were willing to roll up their sleeves and educate themselves about issues; everyone was quite enthusiastic.
\end{abstract}

Open communication and discussion proved to be integral for task force success. Three-quarters of the interviewees reported that they were very satisfied with task force communication, that there was communication at every stage of the project, and that the project was a team effort. One respondent reported, "The task force was wonderful. Everyone was very invested and engaged and everyone did what they were supposed to do." One interviewee stressed the value of the collaborative nature of the task force efforts:

The project was a team effort...The various views of the members really helped the team. Most members agreed with the final recommendations because they were formed as a group.

One-third of the respondents also emphasized the value of having had experts in different areas on the task forces in order to identify worthwhile information. Comments regarding this included: "Different types of experts let us have access to all the different types of data that we needed," and "The number of representatives from DPH that agreed to take the lead in compiling information was good, so that was helpful, it allowed access to information." Overall, there were 13 positive comments about the availability of research findings to the task force members, 3 negative comments and two that could not be classified as either positive or negative.

Some difficulties were encountered within the task forces. Members of one task force divided into subgroups with different foci, but found that when they reconvened as one group they could not reach a consensus on key points. The differences were resolved in a "brainstorming session" in which members discussed the bases of their disagreements and made compromises on final recommendations. Another task force had a similar experience. Overall, however, 14 comments about task force cooperation and communication were positive and only four were negative. There were five negative comments about scheduling problems and some task force members' inability to contribute much time to the project.

\section{Executive Steering Committee}

The task force chairs met periodically as the Executive Steering Committee, as a means to ensure compliance and collaboration among task forces. This assured that everyone knew how other teams were progressing, what sort of data they were utilizing, and what conclusions they were developing. Meetings were used as a venue to coordinate tasks, express concerns, and provide assistance, resources and feedback.

The interviewees who were part of the Executive Steering Committee made many positive comments about the committee's meetings. One respondent commented that everyone at the meetings worked well together and it served as a good forum to share ideas. Another remarked how he really liked the set up of the meetings. He believed them to be consistent and appreciated how they honored a certain time frame. Lastly he noted that the meetings gave chairs a sense that their opinions were valued as well as an opportunity to communicate. Another interviewee discussed his satisfaction with the other Executive Steering Committee members: "It represented a good range of backgrounds and perspectives. All of the members had a real high level of expertise-whether about program issues or relevant research." Another reported, "They worked across task forces to help with the communication between task forces."

Two respondents reported that they were only fairly satisfied with the meetings: one complained that the meetings sometimes did not stay on task, but the other said that while she was dissatisfied initially because the process was slow, she felt by the end the group worked well together as a team. Overall, interviewees made five positive, one negative, and two neutral comments regarding the Executive Steering Committee.

\section{Expert Panel}

Respondents made many positive comments about the Expert Panel meetings and rated them as well run and productive: "positive, well organized, easy to participate, success of addressing key concerns, overall positive recommendations;" "feasibility and sustainability of recommendations, very successful great process." One respondent explained,

It was an outstanding purpose to have a wider group of people with different experience and knowledge: that was needed. Also, if anyone 
had strong opinions about anything they were able to respond and communicate them.

Other respondents described the meeting agendas as concise and clear-ensuring things got done; the task force material as "impressive"; the sharing of information as effective; the collaboration between task forces as good, with much helpful feedback; and the level of discussion as eager and engaging.

At the final Expert Panel meeting, each participant received a packet including all the proposed recommendations and task force leaders presented their group's own recommendations. Respondents discussed modifying, adding or omitting specific recommendations and identified questions that remained unanswered. All described the final recommendations as presented clearly both at the expert panel meeting and in the final written report. One respondent felt that there was insufficient time at the final meeting to modify recommendations in response to feedback and some remained concerned about implementation: "An excellent experience, an extremely well run program, a lot of good ideas but it remains to be seen how they play out."

\section{Recommendations and Implementation}

The seven task forces developed a total of 84 recommendations for program improvement. These recommendations ranged in scope from the simple-e.g., "continue annual cervical and breast exams"-- to the more challenging: "create regional case management networks to enhance collaboration and stimulate best practices." Many recommendations included detailed suggestions for implementation.

In the final project report, these detailed and, in some cases, overlapping recommendations were combined into twelve basic recommendations in four areas: connections with clients and prospective clients, relations with contracting organizations and medical providers, information systems, and staffing [21].

The DPH then hired a health care consulting firm (ProVentive) to work with DPH management, WHN staff and RPPF representatives to assess the legal and financial feasibility of the expert panel recommendations, to weigh the implications of the still evolving Massachusetts Health Care Reform Bill, and to develop an implementation timetable and guidelines. The consulting firm's report was presented four months after the expert panel's final meeting at a conference to which all expert panel members were invited.

The interviewees who attended this presentation agreed that the plans were worthwhile: "I thought [their] strategy and the use of information was very practical;" "I was impressed .... It was a thoughtful step forward from where we left things in June. It was worthwhile, a well organized and thoughtful presentation."

Several of these respondents $(30 \%)$ expressed disappointment that some recommendations were not pursued due to legal and monetary constraints, but most recognized that the process of finalizing Massachusetts health care reform legislation necessarily delayed action on some recommendations.

Big issues were left off the table at that point because of uncertainty, but what they did work out was very sound...There are some disappointments from some Expert Panel members because certain recommendations can't be done in a legal mandate and were therefore left out. But it is great to put those issues on the table and they are included in the final report.

Several others agreed that the project had started an ongoing process, "I think the project will lead to beneficial changes in the WHN, but the project isn't finished yet. It is too early in the process to figure out the value of the recommendations." Four interviewees felt that by the time of the implementation report there should have been more of a commitment to implementation

I think a clearer mandate in terms of the expectation that recommendations would really happen would have improved the project... Of course that's hard though; the money and political aspects of it need to be taken into account.

\section{Overall Evaluation}

Several participants made additional comments about the project in general as a model for translational research.
It was a wonderful project and I thoroughly en- joyed it.
It was a great experience and terrific model for such a project. We figured out a great model.
Nothing [could have been improved in the pro- ject] really- I liked it, it was easy and quick. There were always specific goals and a timeframe was laid out- that was really helpful.

One respondent said that she hadn't participated in this type of project before but had come to recognize the benefits it offered. Half of the respondents felt the project had helped them to realize the limitations of the WHN and half also felt that the project would result in program improvements.

Other interviewees highlighted the people involved in the project.

There were diverse people involved in the decisions- researchers, clinicians, and people in the field. It was good to have many different opinions and many different types of people.

Although tempered by realism about the implementation process, three-fourths of the respondents appraised the project overall as of great value.

Even though not every recommendation would be implemented I still feel that we gave it a good shot and that we were listened to - that's important.

Overall, yes, the project led to beneficial changes in the Women's Health Network. It is good to examine yourself and there is a potential for the network to get better.

There is no question in my mind that the project was very worthwhile - it started a very important conversation. We can use the information to work for social justice and strengthen our cause; there are no questions about that. 


\section{Post-Project Implementation}

Soon after the implementation review, DPH began the implementation process. This process accelerated after the Massachusetts Health Care Reform bill (Chapter 58 of the Acts of 2006) was signed into law in April 2006.

WHN finalized a new coordinated outreach plan that incorporated many of the evidence-based activities defined in the research. Another activity identified in the process was ongoing and consistent training for community health workers. WHN hired a vendor to design an entire course for patient navigators and piloted that course within the next year after the RPPF project. The course is now offered annually. A Medical Advisory board was formed, cardiovascular screening was expanded, administrative responsibilities were streamlined and culturally specific media campaigns were initiated. By the spring of 2008, 40 separate project recommendations had been implemented in whole or in part.

\section{DISCUSSION}

Our review of meeting minutes and other documents has demonstrated that the participatory expert panel process involved consideration of extensive research, frequent communication and exchange of ideas, and a willingness by top management and government officials to sidestep the constraints of hierarchical relationships [24]. Interviews with project participants indicate that expert panel members and task force leaders were very engaged in the process, received support from project staff-although with some shortfalls due to time pressure, and felt that multiple points of view were represented and final recommendations were arrived at fairly.

A successful project requires effective management, committed participants and sufficient resources. In our project, the WHN director and the project leader had between them many years of experience with leadership and evaluation of social programs, while the commitment of participants to the WHN and the women that it serves was in evidence throughout the project. Essential project resources included a $\$ 170,000$ project budget from $\mathrm{DPH}$, a talented administrative assistant and well-prepared research assistants from UMass Boston, active engagement by WHN staff, and the availability of Harvard Medical School meeting facilities. As a result of these arrangements, Executive Steering Committee members received some reimbursement for meeting time, task force meetings could be held in a location close to the worksites of many participants (and include food and conference call arrangements), and participants could have literature reviewed and questions investigated by RAs paid for that contribution.

The cornerstone for the success of any type of translation of research-to-practice is the availability of research of sufficient quality and quantity. In this respect, our PEP project built on two large evaluation research projects funded by WHN in the preceding two years as well as ongoing data collection on WHN clients. The participation of several experienced health care researchers and the availability of RAs who could review additional research literature and investigate other programs helped to place evaluation research findings in a meaningful context. However, we believe that this process could have been improved. Task Force deliberations often focused primarily on members' experiences and those of other programs, while overlooking the potential relevance of evaluation research findings. Ongoing presentations by research experts at task force meetings might have been more effective in highlighting relevant findings than our mid-project "evaluation data workshop" for all panelists.

Due to the concurrent legislative process for implementation of a sweeping health care reform bill that would grant access to virtually all Massachusetts residents, implementation of many RPPF recommendations was delayed. The postexpert panel implementation review also identified some recommendations as unachievable due to legal or resource constraints. However, the process quickly led to development of a new statewide outreach work plan and training program and action on many other recommendations.

Although we believe the participatory expert panel process that we have described can be exported readily to other settings, our project had some limitations that should be avoided. First and foremost, the intersection of our project with the rapid political changes resulting from passage of landmark health care reform legislation in Massachusetts made it impossible for our panel members to know how program eligibility might change. Such a coincidence is unlikely to occur in many such projects, but we suggest that inclusion of attorneys, legislators and politically experienced healthcare experts could help to identify prospective regulatory or legislative proposals that might have implications for proposed program changes. In our project, such an expansion of the panel's membership might have obviated the need for the post-project implementation review and thereby have given Participatory Expert Panel members more of a sense of ownership of the implementation plans. On the other hand, the omission of attorneys, legislators and top administrators from the expert panel facilitated unfettered discussion of program alternatives and may have resulted in more ambitious recommendations. These tradeoffs should be considered carefully in the design of a Participatory Expert Panel.

Our panel process also would have been enriched by explicit consideration of the perspectives of WHN clients, as recommended by Abma [25]. Our failure to include client representatives resulted from our retention at the project's inception of the traditional evaluation research perspective: that is, we felt we were including client perspectives because we had conducted extensive research on program clients and we provided the results of this research to panel members. However, this type of "inclusion" does not provide clients the opportunity to discuss research findings nor to share their perspectives with panelists representing other groups. We did include cancer survivors, family members and members of advocacy groups, but the basis for their inclusion was their employment in the health care system or their academic expertise. We recommend that representatives of program clients and these other groups be included in Participatory Expert Panels and that their perspectives be noted explicitly in task force reports.

Of course, broadening the scope of panel membership and highlighting distinctive group perspectives could alter social dynamics within the panel, particularly in the small task force groups that develop specific recommendations. WHN clients are necessarily from low-income groups and so they and their families are likely to have less education and 
public speaking experience than other panel members. Requiring explicit attention to the perspectives of diverse groups may also increase the propensity for conflict among panel members. We recommend that efforts to expand panel membership and highlight distinctive group perspectives thus be accompanied by a commitment to equitable group process and respecting divergent perspectives.

We also did not include in our expert panel representatives of organizations that contracted with DPH to deliver WHN services. We did not feel that such participants could fairly consider whether changes should be made that might deprive their organization of needed dollars. However, a systematic effort to solicit contractor feedback before the final report was released could have improved some recommendations and increased contractor acceptance of the subsequent changes.

Compression of our project into a six month timeframe was unavoidable due to contracting cycles, but it also created constraints on task force deliberations that could be avoided in other PEP projects. However, the ability of DPH to change requirements for the organizations that deliver WHN services also made it possible to implement quickly some of the important recommendations. In this sense, the rapid project pace enabled more effective public management.

Future PEP projects may be most beneficial if they are reconceptualized somewhat as an ongoing process in which task forces meet as required to review new developments and the entire PEP convenes periodically. This approach would break down Table 1's clear distinction between sequential and simultaneous translation processes and between Participatory Expert Panels and Participatory Action Research projects.

\section{CONCLUSIONS}

Translating research findings into policies and programs "is a difficult and 'messy' enterprise" [26]. This remains no less true today than 100 years ago, when American Sociological Society president Lester Frank Ward's (1906) confident assertion that scientific principles--identified by sociologists--would lead to "future advantageous modification of existing social structures" subsequently foundered. The assumption that policymakers would easily and eagerly use the latest scientific knowledge to reform their practices proved to be hopelessly naive. But while understanding how to effectively translate knowledge into practice has been slow to accumulate, the body of empirically based knowledge available for practical application has multiplied in both quantity and quality [27, 28]. Rigorous designs for evaluation research, meta-analytic procedures for aggregation of research findings, and the availability of systematic research reviews make it possible for decision-makers and managers in diverse programs to find better solutions to the service problems they confront.

Yet it continues to be true that "from an implementation point of view, doing more and better research on a program or practice itself does not lead to more successful implementation." Governmental mandates, political pressures and unanticipated events often result in adoption or modification of programs and policies without first "knowing the current strengths and needs of a community." Constituting a Participatory Expert Panel provides a tool for developing such knowledge ex post and adapting policies and programs accordingly. Because programs are a moving target and adaptation must be ongoing--with periodic revision and reevaluation in light of evidence or political changes--a Participatory Expert Panel can help to ensure that "research findings ...find resonance with existing [local] norms and values" [6].

We are not the first to trumpet the call to action: the National Institutes of Health and other government funding agencies are devoting new resources to increasing awareness of the importance of translation, to stimulating research on the process of translation and to designing more effective means for translation. One widely publicized translation approach that has emerged from this NIH emphasis-termed RE-AIM--emphasizes the importance of creating a "community of practice that has functional processes to facilitate the integration of innovation" [1]. The participatory expert panel process we developed and our findings about its value demonstrate how program maintenance can be facilitated and thus add an important element to this new orientation in research. We close with the recommendation that Participatory Expert Panels should be convened every few years to provide ongoing support and consultation to policy makers as well as intensive reviews for program managers.

\section{REFERENCES}

[1] Fixsen DL, Naoom SF, Blase KA, Friedman RM, Wallace F. Implementation research: A synthesis of the literature. Tampa, FL: University of South Florida, Louis de la Parte Florida Mental Health Institute, The National Implementation Research Network (FMHI Publication \#231). 2005.

[2] Grimshaw J. Improving the scientific basis of health care research dissemination and implementation. Paper presented at building the science of dissemination and implementation in the service of public health. Bethesda MD: Office of Behavioral and Social Sciences Research, National Institutes of Health 2007.

[3] Grimshaw J, Eccles M, Tetroe J. Implementing clinical guidelines: Current evidence and future implications. J Contin Educ Health Prof 2004; 24(Suppl. 1): S31-7.

[4] Saetren H. Facts and myths about research on public policy implementation: out-of-fashion, allegedly dead, but still very much alive and relevant. Policy Studies J 2005; 33(4): 559-82.

[5] Roper W, Thacker SB. Doing good before there's harm. Ann NY Acad Sci 1993; 703(1): 33-40.

[6] Lomas J. Diffusion, dissemination, and implementation: Who should do what? NY Acad Sci 1993; 703(1): 226-37.

[7] Glasgow RE, Marcus Alfred C, Bull SS, Wilson KM. Disseminating effective cancer screening interventions. Cancer Suppl 2004; 101(5): 1230-50.

[8] Sarri R, Sarri CM. Organizational and community change through participatory action research. Admin Soc Work 1992; 16: 99-122.

[9] White GW, Suchowierska M, Campbell M. Developing and systematically implementing participatory action research. Arch Phys Med Rehabil 2004; 85(4 Suppl. 2): S3-S12.

[10] Westhues A, Ochocka J, Jacobson N, et al. Developing theory from complexity: Reflections on a collaborative mixed methods participatory action research study. Qual Health Res 2008; 18(5): 701-17.

[11] French C, True S, McIntyre R, Sciulli M, Maloy K. State implementation of the breast and cervical cancer prevention and treatment act of 2000: A collaborative effort among government agencies. Public Health Rep 2004; 119: 279-85.

[12] Mead Lawrence. Policy research: The field dimension. Policy Stud J 2005; 33: 535-58.

[13] Nutting PA. Making sustainable improvements in primary care practices: Applications of complex adaptive systems theory. Paper presented at building the science of dissemination and implementation in the service of public health. Bethesda MD: Office of Behavioral and Social Sciences Research, National Institutes of Health 2007. 
[14] Baker E, White L, Lichtveld M. Reducing health disparities through community-based research. Public Health Rep 2001; 116: 517-9.

[15] Chambers DA, Kerner JF. Dissemination and implementation PARs: Background, overview, and review challenges. Paper presented at building the science of dissemination and implementation in the service of public health. Bethesda MD: Office of Behavioral and Social Sciences Research, National Institutes of Health 2007.

[16] Jacobson B, Yen L. Health action zones (a way to reduce inequalities in health care). Br Med J 1998; 316: 164-7.

[17] Lavis J, Posada FB, Haines A, Osei E. Use of research to inform public policymaking. Lancet 2004; 364: 1615-27.

[18] Mays G, Hesketh H, Ammerman A, Stockmyer C, Johnson T, Bayne-Smith M. Integrating preventive health services within community health centers: Lessons from WISEWOMAN. J Womens Health 2004; 13: 607-15.

[19] The National Academies. The National Academies: Our Study Process. Washington, DC: National Academies Press. Retrieved 1/18/2008. Available from: http://www.nationalacademies.org/ studycommitteprocess.pdf

[20] Schutt R, Fawcett F. Case management in the women's health network: A comprehensive evaluation for the department of public health, commonwealth of Massachusetts. The Department of Public Health, UMass Boston, Harvard Medical School, Women's Health Network. Boston 2005

[21] Schutt R. The Women's Health Network: Reviewing the past, planning the future. UMass Boston, Harvard Medical School, The Department of
Public Health, Women's Health Network. Boston 2005. Available from: http://www.faculty.umb.edu/russell_schutt/RESEARCH\%20REPORT S.htm

[22] Schutt R, Cruz ER, Ayanian JZ, et al. The women's health network project, reviewing the past, planning the future. Women's Health Network, the Department of Public Health, University of Massachusetts Boston and Harvard Medical School 2006. Available at: http://www.massachusettsmentalhealthcenter.org/whnrppf

[23] Estabrook R. Reviewing the process and outcomes of the Women's Health Network's "Reviewing the past, planning the future" project. Master's thesis directed by Russell K. Schutt. Boston: Graduate program in applied sociology, University of Massachusetts Boston 2006 .

[24] Ferlie E, Shortell S. Improving the quality of health care in the United Kingdom and the United States: A framework for change. Milbank Q 2001; 79: 281-315.

[25] Abma TA. Patients as partners in health research. Eval Health Prof 2006; 29: 424-39.

[26] Auerbach J, Figert A. Women's health research: Public policy and sociology. J Health Soc Behav 1995; 35: 115-31.

[27] Rabito F, White L, Shorter C. From research to policy: Targeting the primary prevention of childhood lead poisoning. Public Health Rep 2004; 119: 271-8.

[28] Zerigon-Hakes A. Translating research findings into large-scale public programs and policy. Long-Term outcomes of early childhood programs 1995; 5: 175-191.

This is an open access article licensed under the terms of the Creative Commons Attribution Non-Commercial License (http://creativecommons.org/licenses/by$\mathrm{nc} / 3.0 /$ ) which permits unrestricted, non-commercial use, distribution and reproduction in any medium, provided the work is properly cited. 